\title{
Eaeu common regional currency
}

\author{
Galina Vladimirovna Pliushcheva* \\ MSIIR, Udaltsova st., 71, 2, 24, 119454 Moscow, Russian Federation
}

\begin{abstract}
The operation and development of the economies of the EAEU countries is subject to the influence of external economic factors, while the single currency will eliminate the risks associated with the restriction of the use of the dollar due to sanctions and will reduce transaction costs. The article offers an approach for the formation of a single internal currency within the EAEU that is based on the following key provisions: firstly, in modern conditions, the role of digital financial assets (and, consequently, cryptocurrency) is gaining importance in economic regional interaction; secondly, the Russian Federation and the Republic of Kazakhstan have not fully legitimized digital financial assets, but partially recognize them, while preserving the resource-specific nature of the financial and economic sphere; thirdly, the global trend for the demand for an alternative type of money should be considered. The proposed approach is addressed to small regional economic and political associations, which makes it possible to fairly quickly consider current and future changes in pricing of one unit of currency. In addition, the proposed approach can be scaled based on the growing influence of the previous and new members of the regional economic association.
\end{abstract}

\section{Introduction}

The formation of a single currency for various economic interstate integrations has its drawbacks and benefits. Among the former, it is worth highlighting the lack of opportunities for hedging currency risks, an increase in consumer spending (and, hence, inflation), an increase in the opportunism of economic agents, etc. On the other hand, there are objective advantages: an increase in investment volumes, a reduction in dependence on fluctuations in leading world currencies, stabilization of financial markets and simplification of mutual settlements (both in the corporate and consumer sectors).

This article proposes to explore issues related to the formation of a EAEU single currency on the platform of digital and resource money (i.e., cryptocurrencies and energy currencies).

With the large-scale dissemination of information and communication technologies, the dominant state and its control in the financial sector began to decline.

The second important point, which reduced the position of the state, was a decrease in confidence in the main (reserve) world currencies, which was due to global geopolitical changes (the end of the era of "Westernization", the formation of a "multipolar world", the shift of world centers of economic attraction from the West to East and to Asia) [23].

*Corresponding author: galina.pluscheva@gmail.com 
Fluctuations and critical volatility against this backdrop of exchange rates have shown the inability of the global financial system to withstand such shocks. Therefore, it is quite natural that national economies have formed a demand for new financial technologies, the response to which was new types of money [11], [16]. Usually, digital (cryptocurrencies) and resource (energy currencies) types of money are distinguished.

Cryptocurrency is also a digital currency generated by a special mathematical algorithm and issued by any individual who has the necessary software and hardware for this. This is precisely the key difference between cryptocurrencies and other types of electronic money - the method of emission and its decentralization; at the same time, the cryptocurrency must have a cryptographic proof of value (this requires a software algorithm) and transparency of transactions (a register that will reflect the entire chain from creation units of currency before its use in all calculations) [15].

Cryptocurrency, on the one hand, is a type of digital financial asset, which, of course, is recognized by all researchers from a scientific and a practical point of view - experts on financial markets [21 P.113-146]. On the other hand, there is a legal paradox - states with a strong centralization of the financial sector, as well as with a high share of state participation in the operation of the financial and credit institution (directly as a macroregulator and indirectly - through financial and credit organizations), which have a limited circulation of cryptocurrencies (as a means of payment), but de facto have not completely prohibited the activity on the creation of cryptocurrencies, although have made some attempts [18], [20 P. 397-404].

In this sense, the Republic of Belarus occupies a special position in the market of digital financial assets, and in particular, cryptocurrencies. At the end of 2017, Belarus adopted a special decree ("On the Development of the Digital Economy"), which legalized the circulation of cryptocurrency in the country and smart contracts (blockchain technology for concluding and maintaining commercial contracts using a special computing algorithm). In Russia and Kazakhstan, the situation with the use of cryptocurrencies is far from unambiguous [Ошибка! Источник ссылки не найден. Р.121-124], [10 P.151-156]. At the same time, despite the legal ban on the use of cryptocurrencies in Russia, it is not possible to believe that such a situation will exist for a long time.

In general, resource money (energy currencies) deserves the same ambiguous assessment, which, according to the authors' idea, should be based on some industrial indices or electricity or even a labor resource. Having reviewed scientific publications and discussions, we can give a definition of resource money - it is a type of money provided by natural resources such as oil, gas, and electricity [9], [6], [5], [2], [13].

A number of Russian and foreign scientists are skittish about digital financial assets, including cryptocurrencies, indicating that this is a trigger for a new financial crisis in the world economy [12 p. 88-99], [19]. Nevertheless, today the Chinese economy has already introduced its digital yuan. The European Central Bank has just registered the name of the digital euro; at the same time, there is no doubt that this type of digital money will appear in circulation in the near future.

The existing digital Chinese yuan, the future of the digital euro and other digital currencies of central banks will be based on the same blockchain technology as existing and unrecognized digital currencies in most countries. At the same time, we do not have any significant statistics on changes in the digital yuan. That is why, the model described below will use statistical data from one of the most popular existing digital currencies, meaning that in the future the model can be modified by replacing the data on the currencies used with the most used in the world within the legal field.

It is worth noting that today Western European countries (the main importers of hydrocarbons) have begun to demonstrate a trend towards the development of renewable energy, which would reduce dependence on energy imports, including from Russia and 
Kazakhstan. Therefore, the use of new types of currency (resource money) requires special institutional conditions in the form of a normally functioning single economic space (for example, on the basis of the EAEU). Besides, it is important that the share of the EAEU in the world economic turnover is constantly growing; at present, the three leading economies of the EAEU (Russia, Kazakhstan and Belarus) form less than 7\% of world GDP.

\section{Materials and Methods}

According to independent consulting agencies in the three main states integrated into the EAEU (Russia, Belarus, Kazakhstan), the total volume of electronic money alone (that is, without cryptocurrencies) amounted to about 1.6 trillion rubles in 2014; but already at the beginning of 2019 the total volume of settlements with the use of digital money amounted to about 3.5 trillion rubles, and more than a third of the population of the Russian Federation, the Republic of Belarus, and the Republic of Kazakhstan have electronic wallets [14].

The current analysis and further modeling are based on the values of the most popular currencies; but in the future, it will be necessary to rely on possible legal and more stable cryptocurrencies than Bitcoin and Ethereum.

Considering the concept of the transition from non-equilibrium fuel to equilibrium nonfuel energy [3 p.58-59], within which the "era of oil" ends [7], [17] should abandon the development of an alternative currency based on the market price of oil and leave for the further development of electricity and natural gas.

To develop a common currency suitable for mutual settlements within the EAEU, data on the market price of cryptocurrencies and the market price of two energy goods should be used. It should be borne in mind that cryptocurrencies rather than energy products are overvalued in terms of the market.

The second most important point, in fact, is that only three states - the Russian Federation, the Republic of Belarus, and the Republic of Kazakhstan - form the current economic and political agenda in the EAEU. The rest of the states - Armenia and Kyrgyzstan - are less involved in the integration and reintegration processes.

That is why, the development of a common currency considers the specialization of the economies of the three states under consideration: the Republic of Belarus, the Republic of Kazakhstan, and the Russian Federation. The main export product of Kazakhstan and Russia is hydrocarbon (mineral) raw materials (mainly of low value added), and the main export product of Belarus is agricultural raw materials and the final traditional products of the agro-industrial sector. Consequently, in Kazakhstan and Russia, resource money can become new modern money, while Belarus has a different situation - resource money is banned here, and the necessary institutional conditions for the circulation of electronic money are only being formed.

\section{Model}

The concept of creating a common energy market for the EAEU is assigned to 2025-2030, as well as the prospects for creating a single financial market. It is likely that in the next 5 to 10 years in the Republic of Belarus acceptable conditions will be created for the circulation of digital financial assets, including cryptocurrencies. It should also be noted that the national currencies of Russia, Kazakhstan, and Belarus are quite volatile not only in relation to each other, but also relative to the studied period of time. Accordingly, for further calculations, it is necessary to form a stable base against which measurements and the range of variation in the price of resource and electronic money will be carried out. In 
addition, it is important to consider the share of Russia, Belarus and Kazakhstan in mutual trade. It is proposed to use natural gas and electricity as resource money, and Bitcoin and Ethereum cryptocurrencies as digital money. It is obvious that the use of this type of cryptocurrency is primarily analytical. These parameters can be replaced with others that reflect the digital context. Changes in the prices of cryptocurrencies and energy resources can be considered as corrective markers in the formation of the value of the settlement currency for a small set of countries interacting within regional economic systems [22 P.127-139]. Corrective markers will reflect the market reaction, including unforeseen events with a low probability, but a large impact - the Black Swans events [24].

Consequently, when forming a EAEU common internal currency a toolkit for calculating a corrective marker should be primarily created. We believe the following formula can be used for the ratio of the range of variation in the price of one unit of resource or digital money for $n$ periods to the average weighted price of one unit of resource or digital money for $n$ periods:

$$
c m=\frac{s v_{n}}{w a(e ; r)_{n}}
$$

Where:

$\mathrm{cm}$ is the value of the corrective indicator (hereinafter the marker);

$s v_{n}$ is the range of variation in the price of one unit of resource or digital money for $n$ periods;

$w a(e ; r)_{n}$ is the weighted average price of one unit of resource or digital money for $n$ periods.

As we use four types of digital and resource money (respectively, Bitcoin, Ethereum, electricity, and natural gas), then we should integrate the obtained values into one correction marker:

$$
\begin{aligned}
c m_{\theta} & =\sqrt{c m_{b} * c m_{\theta p}} \\
c m_{r} & =\sqrt{c m_{\theta \theta} * c m_{n g}}
\end{aligned}
$$

Where:

$\mathrm{cm}_{e}, \mathrm{~cm}_{r}$ is the value of the correcting marker of electronic and resource money, respectively;

$c m_{b}, c m_{e p}$ is the value of the correction marker of the Bitcoin unit and the Epherium unit, respectively;

$c m_{e e}, c m_{n g}$ is the value of the correction marker of the units of electricity and natural gas, respectively.

As the rates of the national currencies of Russia, Belarus, and Kazakhstan, which make up the core of the EAEU, are not stable, a need arises to form a currency base to calculate the value of a unit of the national currency. To do this, use the reserve currencies of the dollar and the euro, as the most used, as well as the Chinese yuan, as the currency of the country with the second largest economy in the world, and having a significant impact on the world economy and finance:

$$
c b=w a(d, e, y)_{g d p}
$$

Where: 
$c b$ is the value of the currency base, expressed in units of the national currency (Russian ruble, Belarusian ruble, or Kazakh tenge);

$w a(d, e, y)_{g d p}$ is the weighted average price of one US dollar, euro, and Chinese yuan (the weight is the share in world GDP).

The next step in the calculations is to determine the role of each national currency in mutual trade within a regional economic association. Here it is advisable to use the share of each country in the volume of mutual trade. Considering that over the past five years the distribution of the shares of mutual trade in the EAEU remains approximately constant, we will assume that Russia owns $65.1 \%$, Belarus - about $23.2 \%$, Kazakhstan - about $9.6 \%$ of the total volume of mutual trade with by all members of this regional economic organization.

Then the unit price of a EAEU common internal currency will be determined as follows:

$$
s c l=\sum c b_{i} * \Delta m t_{i} * c m_{\theta ; r}
$$

Where:

$c b_{i}$ is the value of the currency base of the $i$-th member of the association (in our case, Russia, Kazakhstan, and Belarus), expressed in national currency units;

$\Delta m t_{i}$ is the share of the $i$-th member of the association (in our case, Russia, Kazakhstan, and Belarus) in mutual trade with other members of the association;

$\mathrm{cm}_{e ; r}$ is respectively, a correction marker for electronic or resource money (for Russia and Kazakhstan - a marker for resource money, for Belarus - electronic money).

The next step is to assess the practical implementation of this approach to modeling the exchange rate using the example of three states that form the core of the EAEU.

Table 1. Calculation of the unit price of the EAEU internal currency

\begin{tabular}{|l|l|l|}
\hline \multicolumn{1}{|c|}{ Indicator } & Value & $\begin{array}{l}\text { Share in } \\
\text { mutual } \\
\text { trade }\end{array}$ \\
\hline Digital money adjustment marker & 1.28 & \\
\hline Resource money adjustment marker & 0.85 & 0.651 \\
\hline Currency base of the Russian Federation & 37.54 & 0.232 \\
\hline Currency base of the Republic of Belarus & 1.18 & 0.096 \\
\hline Currency base of the Republic of Kazakhstan & 204.52 & 0.72 \\
\hline The price of a EAEU common currency, un. acc. & & 88.72 \\
\hline
\end{tabular}

At this stage, it is obvious that the price of a EAEU common currency is formed mainly due to the contribution to the mutual trade of the Russian Federation and due to the price of the national currency of the Republic of Kazakhstan. The Republic of Belarus has the least influence on the formation of the price of a EAEU common currency (as well as other participants).

Thus, on the one hand, the creation of a common currency is an objective necessity for the EAEU, as external economic conditions do not contribute to the competitive development of the economies of this interstate integration. However, on the other hand, the lack of institutional stability and continuity in the management of socio-economic processes is the factor that can weaken the position of the single currency in the future, and it will not stimulate the achievement of the set goals (for example, an increase in the inflow of investments, etc.). Therefore, in the economies of Russia, Belarus, and Kazakhstan, structural and institutional reforms should be continued, and alternative models for the formation of a single currency, for example, using digital and resource money, should be considered as a potentially promising and relevant platform for exchange rate formation. 


\section{Results and Discussion}

The above-developed practice-oriented methodological approach can be used to form a common internal currency within the EAEU. This approach is based on the following key points:

- firstly, in modern conditions, the role of digital financial assets (and, consequently, cryptocurrency) is growing in economic regional interaction. Therefore, the financial and economic environment of the Republic of Belarus will be focused on creating special institutional conditions for the spread of digitalization, including in monetary relations;

- secondly, the Russian Federation and the Republic of Kazakhstan have not fully legitimized digital financial assets but partially recognized them, while preserving the resource-specific nature of the financial and economic sphere;

- thirdly, considering the trend for the request for an alternative type of money, it is proposed to use the change in the cost of electronic and/or resource money as corrective markers of the price of one unit of the single internal currency of the EAEU.

- The weighted average price of three reserve currencies (US dollar, euro, Chinese yuan) is used as the monetary base for calculations. The calculation of the price of one unit of the single internal currency of the EAEU considers the contribution of the three core states to mutual trade with all members of the association, as well as the specialization of their economies (resource or digital).

\section{Conclusion}

The proposed approach is addressed to small regional economic and political associations, which makes it possible to fairly quickly consider current and future changes in pricing of one unit of settlement currency (i.e. differentiate its price based on the influence of market and non-market circumstances). In addition, the proposed model can be scaled based on the growing influence of the previous and new members of the regional economic association. The chosen approach ensures a flexible response to changes in the economy and meets modern technical solutions in information security. This model is analytical. The components of the digital and foreign exchange money market reflect the situation in the financial markets and the world and consider in their price even unforeseen events, which, as a rule, are not expected but significantly affect the price changes. The choice of using a digital or resource marker emphasizes the economic focus of the country, and the aggregation of data into a single formula helps to assess the contribution of each country to the price of a common currency.

The proposed common currency can be used in settlements between countries, and each of the countries can obtain it according to the principle of using the bancor proposed by J.M. Keynes [8] and further transferable ruble (hereinafter TR) in relation to the regional CMEA organization. TR was used in the following areas: to express the value of contracts for the supply of goods and services, works, to serve as the currency of payment with the participation of the IBEC, as credit money (in fact, TR was issued to the country for the supply of goods and for various investment projects), that is, TR was used to calculate debts and obligations of enterprises participating in international relations. TR also served as a store of value for international banks such as IBEC and the International Investment Bank (IIB), as well as for financing the activities of a number of CMEA organizations. The rules for using the transferable ruble stimulated countries to equalize their balances of payments by the end of the year, and in case of any surplus or deficit of an asset, countries would 
have to pay interest or devalue, and in the event of a significant surplus, revaluation and stimulate the export of capital, otherwise the surplus would be confiscated.

The Eurasian Economic and, in the future, the currency union also needs its own supranational regional management and regulation system. Certain results on this task have already been achieved. In January 2006, the Eurasian Bank for Economic Development (EBED) was established. In fact, the bank is engaged in financing and technical assistance of projects vital for integration. It is also worth noting the operation of the financial message transmission system based on the information and telecommunications system of the Central Bank of the Russian Federation, which already implements the transmission of message data in its own format, and in the future can completely replace the SWIFT system.

In the long term, states need to be prepared for supranational management of the monetary and financial sphere, which may even present some difficulties on a psychological level. Nevertheless, talking about a single currency is impossible without a single supranational regulator. In this case, it will also be necessary to have a unified system and principles of deposit insurance, the development of unified methods for assessing insolvent organizations and their additional capitalization. In this case, countries can go at least three ways: create an independent supranational regulator following the example of the Eurozone, follow the policy of the regulator of the leading country, that is, Russia, or, the most acceptable option at the moment, limit the functions of a supranational bank, leaving the countries the ability to independently conduct monetary policy and use national money for internal payments.

Now one can hardly imagine the implementation of a common monetary policy in the countries. For example, if the same monetary policy is carried out in Belarus as it is now in Russia, unemployment may significantly increase due to the current excessive employment (according to some estimates, it reaches 20\%), as well as the number of unprofitable enterprises in the real sector of the economy, which are now being supported, will increase. government through emission. All this can lead to a decrease in production and GDP. That is why, before the creation of a single currency space, time is needed to at least partially improve the overall market economic climate. In addition, the clause on financial discipline, as well as possible measures of the state deficit is necessary for inclusion in the EAEU agreement [4 P.182-183].

The need for practice-oriented developments along with methodological developments focused on the creation of a single currency to create conditions for a dynamically stable social and economic development of the Eurasian Economic Union is obvious.

\section{References}

1. O.V. Azoeva, A.M. Ermatov, Fundamental science and technologies - promising developments, 121 (2008)

2. R.I. Bekkin, Problems of the modern economy, 3, 213 (2010)

3. V.V. Bushuev, A.I. Gromov, Energy sources and consequences of the global crisis of the 2010s, 88 (2012)

4. E.L. Davydenko, Trends and prospects for the development of the Eurasian Economic Union in the context of the experience of European integration and global challenges: a collection of articles based on the proceedings of the International Scientific and Practical Conference (Moscow, April 21, 2015), 182 (2016)

5. V.Iu. Katasonov, Katasonov on the "golden stranglehold" and bankers, http://gold.ru/

6. M.I. Gvardeitsev, P.G. Kuznetsov, V.L. Rosenberg, Mathematical support of management, Measures for the development of society, 2, 222 (2016) 
7. N. Nakitsenovich, A. Gritsevskii, A. Griubler, K. Riakhi, World prospects for natural gas, 84 (2001)

8. S.R. Moiseev, International financial markets and international financial institutions, 245 (2002)

9. J.F. Nash, Russian management journal, 6(4), 3 (2008)

10. V.E. Ponomarenko, Legal science, 2, 151(2018)

11. A.F. Hayek, Private money, 21(1996)

12. A.S. Sherstobitov, O.A. Kusik, Social and humanitarian knowledge, 4(2), 88 (2018)

13. T.S. Iurkova, Problems of modern economics, 4, 186 (2010)

14. O. Iasko, Cryptocurrencies in Russia 2017, https://home.kpmg/

15. A. Narayanan, J. Bonneau, E. Felten, A. Miller, S. Goldfeder, Bitcoin and cryptocurrency technologies: a comprehensive introduction (2016) https://www.scirp.org

16. M. Friedman, Anna J. Schwartz, Money in historical perspective, 289 (1987) http://www.nber.org/

17. R. Fuller, Kuromiya, Critical path, NY: Norton \& Company, 471 (1981)

18. J. Herbert, A. Litchfield, Proceedings of the 38th Australasian Computer Science Conference (ACSC 2015), 27, 30 (2015)

19. J. Lansky, Journal of systems integration, 9(1), 19 (2015)

20. W.J. Luther, The independent review, 20(3), 397 (2016)

21. M. Pilkington, Blockchain technology: principles and applications, Research handbook on digital transformations, Université Bourgogne Franche Comte, 39 (2016) https://papers.ssrn.com/

22. S. Rossi, Economic crises and emerging market economies, 127 (2016)

23. D. Sornette, Why stock markets crash: critical events in complex financial systems, 448 (2017)

24. N. Taleb, The Black Swan: The impact of the highly improbable, 400 (2007) 